Corrigendum

\title{
Corrigendum to "Study on the Therapeutic Benefit on Lactoferrin in Patients with Colorectal Cancer Receiving Chemotherapy"
}

\author{
Tarek M. Moastafa, ${ }^{1}$ Alaa El-Din Elsayed El-Sissy, ${ }^{2}$ \\ Gehan K. El-Saeed, ${ }^{3}$ and Mai Salah El-Din Koura ${ }^{4}$ \\ ${ }^{1}$ Faculty of Pharmacy, Tanta University, Tanta, Egypt \\ ${ }^{2}$ Pharmacology Department, Faculty of Pharmacy, Tanta University, Tanta, Egypt \\ ${ }^{3}$ Faculty of Medicine, Menoufiya University, Shibin el-Kawm, Egypt \\ ${ }^{4}$ Hospital of Menoufiya University, Shibin el-Kawm, Egypt
}

Correspondence should be addressed to Mai Salah El-Din Koura; dr.pharmasist@yahoo.com

Received 7 May 2015; Accepted 24 May 2015

Copyright (C) 2015 Tarek M. Moastafa et al. This is an open access article distributed under the Creative Commons Attribution License, which permits unrestricted use, distribution, and reproduction in any medium, provided the original work is properly cited.

Changes in the paper entitled "Study on the Therapeutic Benefit on Lactoferrin in Patients with Colorectal Cancer Receiving Chemotherapy" are as follows:

(1) Title of Table 4 was changed.

(2) Tables 5 and 6 became one table, currently numbered 5 , containing updated information compared to the published paper. 
TABLE 4: Differences between parameters values before treatment and three months after treatment indicate improvement of all parameters after treatment among the studied patients in test group with colorectal cancer receiving chemotherapy and bLF (results represented as mean $\pm \mathrm{SD}$ values).

\begin{tabular}{lcc}
\hline Parameter & $\begin{array}{c}\text { Control } \\
\text { mean } \pm \text { SD }\end{array}$ & $\begin{array}{c}\text { LF } \\
\text { mean } \pm \text { SD }\end{array}$ \\
\hline BUN $(\mathrm{mg} / \mathrm{dL})$ & $0.3 \pm 2.9$ & $4.8 \pm 3.14^{*}$ \\
Serum creatinine $(\mathrm{mg} / \mathrm{dL})$ & $0.078 \pm 0.22$ & $0.078 \pm 0.22$ \\
AST $(\mathrm{IU} / \mathrm{L})$ & $0.306 \pm 7.29$ & $12.44 \pm 13.22^{*}$ \\
ALT $(\mathrm{IU} / \mathrm{L})$ & $0.88 \pm 5.4$ & $6.88 \pm 11.27^{*}$ \\
Serum LF $(\mathrm{ng} / \mathrm{mL})$ & $0.002 \pm 0.011$ & $0.15 \pm 0.16^{*}$ \\
Serum GST enzyme $(\mathrm{ng} / \mathrm{mL})$ & $0.000 \pm 0.002$ & $0.206 \pm 0.089^{*}$ \\
INF- $\gamma(\mathrm{pg} / \mathrm{mL})$ & $0.1 \pm 0.27$ & $1.62 \pm 0.66^{*}$ \\
WBCs $\left(* 10^{3} \mathrm{cell} / \mu \mathrm{L}\right)$ & $0.146 \pm 0.72$ & $1.06 \pm 1.18^{*}$ \\
Platelet $\left(* 10^{3} / \mathrm{mm}{ }^{3}\right)$ & $25.40 \pm 39.06$ & $36.46 \pm 12.26^{*}$ \\
CEA $(\mathrm{ng} / \mathrm{mL})$ & $8.37 \pm 23.91$ & $13.41 \pm 21.91^{*}$ \\
RBCs $\left(* 10^{6} / \mu \mathrm{L}\right)$ & $0.111 \pm 0.222$ & $0.514 \pm 0.126^{*}$ \\
Neutrophil $(\%)$ & $0.93 \pm 4.7$ & $11.86 \pm 1.45^{*}$ \\
Hb $(\mathrm{g} / \mathrm{dL})$ & $0.52 \pm 1.2$ & $1.97 \pm 0.35^{*}$ \\
\hline
\end{tabular}

Note: ${ }^{*}$ significant difference $P \leq 0.05$. 
TABLE 5: Mean percent of change of all parameters after compared to before treatment among the studied patients with colorectal cancer receiving chemotherapy (treated with recombinant human lactoferrin and not).

\begin{tabular}{lccc}
\hline Parameter & LF & Control & mean \pm SD \\
& mean \pm SD & $1.65 \% \pm 5.36 \%$ & \\
\hline Serum LF (\%) & $111.17 \% \pm 96.69 \%$ & $\downarrow-0.26 \% \pm 0.41 \%$ & $0.001^{*}$ \\
Serum GST enzyme (\%) & $31.83 \% \pm 19.83 \%$ & $\downarrow-0.33 \% \pm 0.84 \%$ & $0.001^{*}$ \\
INF- $\gamma(\%)$ & $5.12 \% \pm 2.18 \%$ & $95.92 \% \pm 144.93 \%$ & $0.001^{*}$ \\
CEA (\%) & $\downarrow-47.45 \% \pm 20.91 \%$ & $7.92 \% \pm 21.44 \%$ & $0.001^{*}$ \\
BUN (\%) & $\downarrow-28.18 \% \pm 10.47 \%$ & $13.03 \% \pm 24.20 \%$ & $0.0001^{*}$ \\
Serum creatinine (\%) & $\downarrow-5.24 \% \pm 37.15 \%$ & $4.63 \% \pm 29.46 \%$ & 0.122 \\
AST (\%) & $\downarrow-27.50 \% \pm 15.13 \%$ & $3.97 \% \pm 15.96 \%$ & $0.001^{*}$ \\
ALT (\%) & $\downarrow-5.66 \% \pm 46.83 \%$ & $\downarrow-2.56 \% \pm 5.06 \%$ & 0.457 \\
RBCs (\%) & $11.65 \% \pm 2.15 \%$ & $\downarrow-3.75 \% \pm 9.53 \%$ & $0.0001^{*}$ \\
Hb (\%) & $17.91 \% \pm 2.76 \%$ & $\downarrow-1.40 \% \pm 11.09 \%$ & $0.0001^{*}$ \\
WBCs (\%) & $21.51 \% \pm 18.27 \%$ & $\downarrow-10.38 \% \pm 14.81 \%$ & $0.0001^{*}$ \\
Platelet (\%) & $18.51 \% \pm 4.56 \%$ & $\downarrow-1.08 \% \pm 9.33 \%$ & $0.0001^{*}$ \\
Neutrophil (\%) & $26.31 \% \pm 2.11 \%$ & $0.0001^{*}$ \\
\hline Not $\%$
\end{tabular}

Note: ${ }^{*}$ significant $(P \leq 0.05)$. 


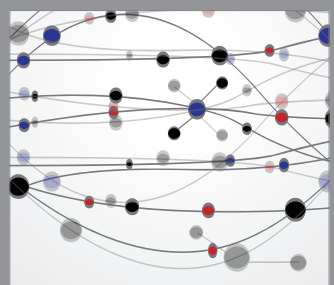

The Scientific World Journal
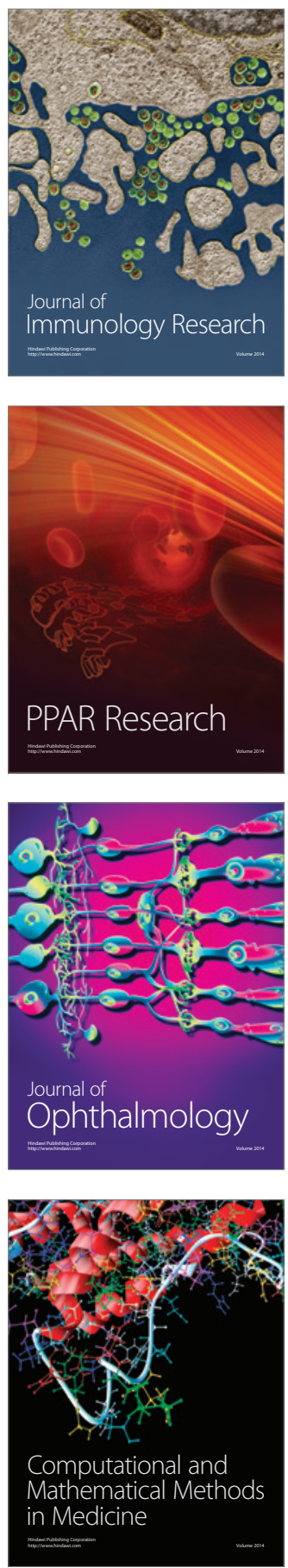

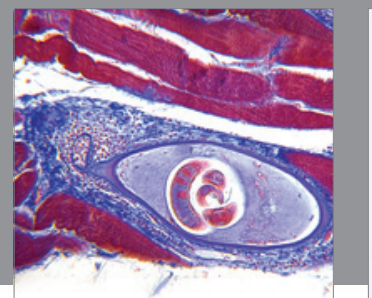

Gastroenterology

Research and Practice
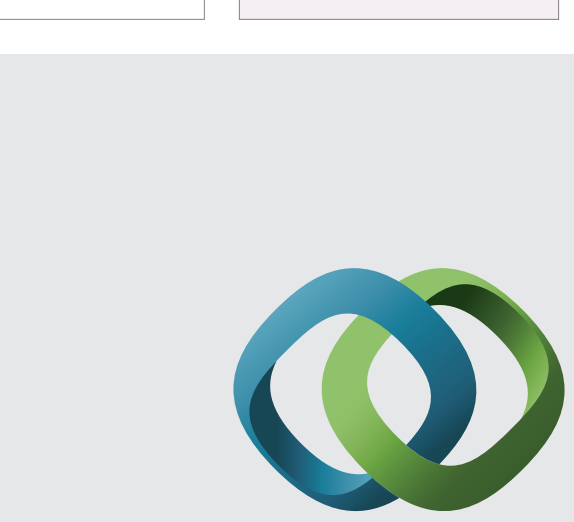

\section{Hindawi}

Submit your manuscripts at

http://www.hindawi.com
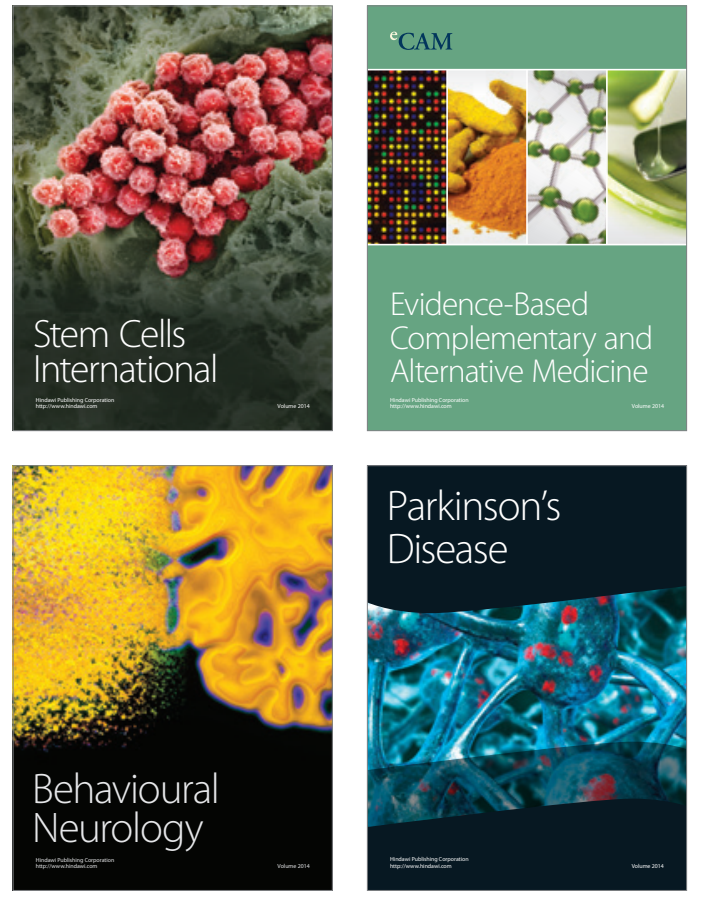
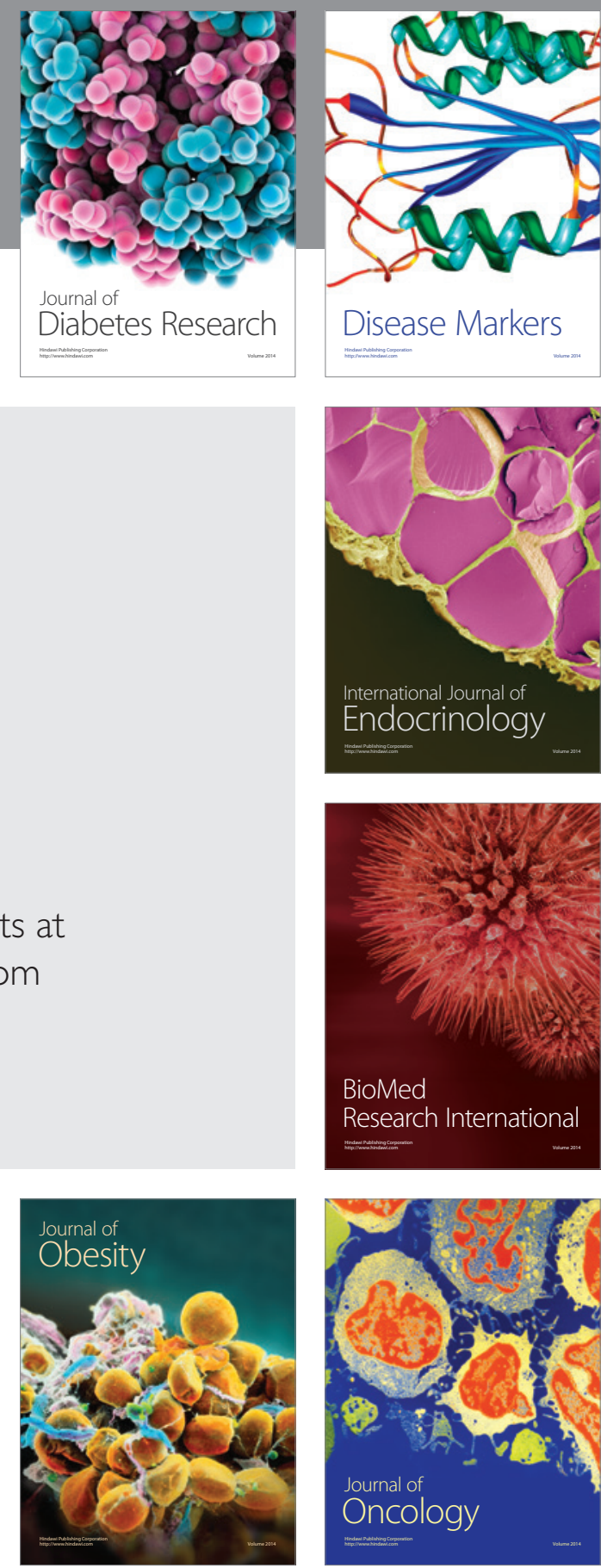

Disease Markers
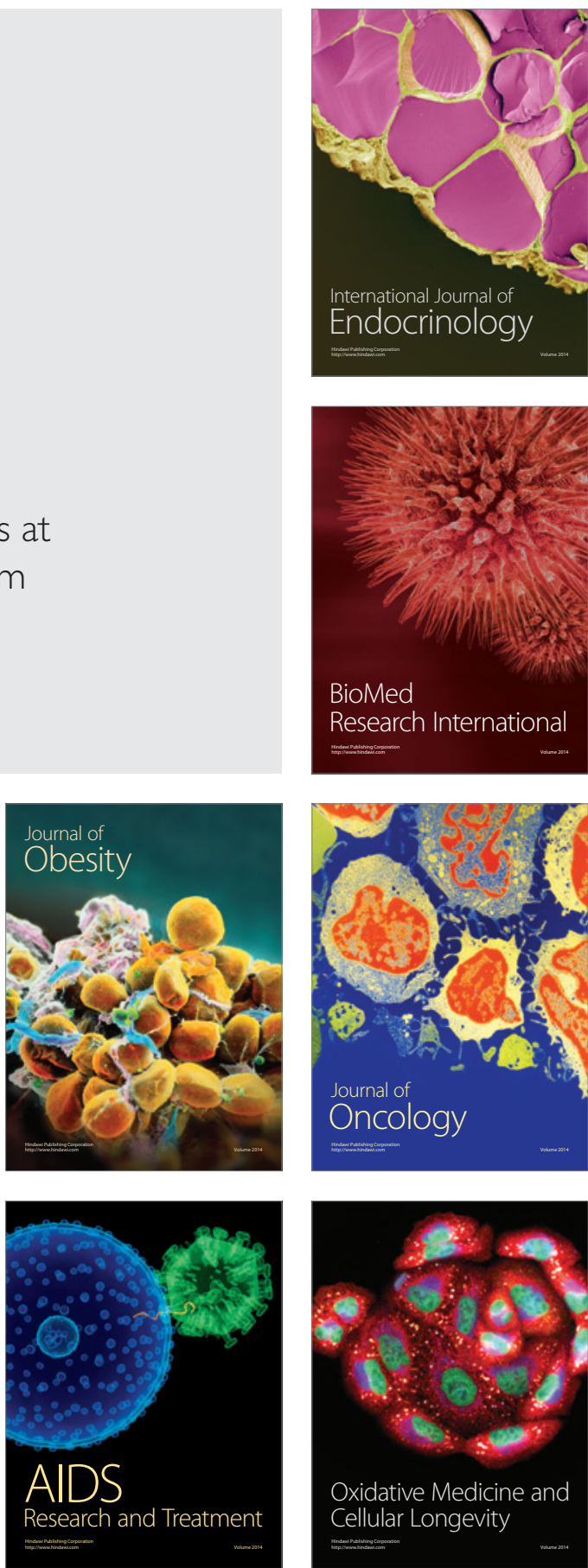